\title{
Solubility Enhancement of Lornoxicam by Crystal Engineering
}

D. D. GADADE ${ }^{*}$, D. A. KULKARNI, P. B. RATHI, S. S. PEKAMWAR ${ }^{1}$ AND S. S. JOSHI

Shri Bhagwan College of Pharmacy, CIDCO N-6, Aurangabad-431 003, ${ }^{1}$ School of Pharmacy, S. R. T. M. University, Vishnupuri, Nanded-431 606, India

\section{Gadade, et al.: Crystal Engineering of Lornoxicam}

\begin{abstract}
An attempt was made to improve the solubility and physicochemical properties of the poorly soluble lornoxicam by crystal engineering with different coformers. Nineteen different coformers were screened during this study. Cocrystals were prepared by neat grinding method. The prepared cocrystals were evaluated for solubility, powder characteristics, assay and in vitro dissolution study. The solid state property was characterized by differential scanning calorimetry, Fourier transform infrared spectroscopy, powder $X$-ray diffraction analysis and Raman spectroscopy. Maximum solubility and dissolution rate were observed with cocrystal prepared using saccharin sodium. Cocrystallization leads to increased solubility and improved in vitro dissolution of lornoxicam.
\end{abstract}

Key words: Coformer, cocrystal, lornoxicam, solubility, dissolution, crystal engineering

The major challenge to the design of oral dosage forms lies with their poor bioavailability. The most common causes of low oral bioavailability are poor solubility and low permeability of active pharmaceutical ingredient (API $)^{[1]}$. Multiple approaches have been adopted to improve the solubility of poorly water soluble APIs including micronization ${ }^{[2]}$, complexation with cyclodextrins $^{[3]}$, cosolvency ${ }^{[4,5]}$, solid dispersions ${ }^{[6]}$, salt forms ${ }^{[7]}$, nanoparticles ${ }^{[8]}$ and surfactants ${ }^{[9]}$, etc. Cocrystals are a class of multicomponent molecular crystals demonstrated to enhance the solubility, bioavailability and/or stability of API, which has been proposed as a unique crystal engineering approach to alter the physicochemical properties of compounds ${ }^{[10-12]}$. According to recently published guidance by the United States Food and Drug Administration (USFDA) cocrystals are defined as, 'crystalline materials composed of two or more molecules within the same crystal lattice ${ }^{[13]}$.

Lornoxicam (fig. 1) is a non-steroidal antiinflammatory drug (NSAID) of oxicam class with analgesic, antiinflammatory and antipyretic properties and its daily dose is $8 \mathrm{mg}^{[14]}$. It belongs to Biopharmaceutical Classification System (BCS) - class II substance with low solubility and high permeability. It was reported to be practically insoluble in water and has low to variable bioavailability. The reported low aqueous solubility
$(0.0385 \pm 0.01 \mathrm{mg} / \mathrm{ml})$ at ambient temperature impairs its dissolution in the upper gastric fluid, which alters bioavailability and hinders its therapeutic application and thereby onset of action or activity ${ }^{[15-17]}$. The problem of low solubility of a compound can be solved by crystal engineering approach while maintaining its stability. This research has two principle objectives; one to screen coformers through co-crystallization with lornoxicam to enhance its solubility and dissolution rate and the second to characterize and evaluate the selected cocrystal form of lornoxicam. In the current study 19 different coformers were screened to prepare lornoxicam cocrystals by neat grinding method. The cocrystals with optimum solubility were characterized using differential scanning calorimetry (DSC), Fourier transform infrared spectroscopy (FTIR), powder X-ray diffraction (XRD) analysis and Raman spectroscopy.

\section{MATERIALS AND METHODS}

Lornoxicam was received as a gift sample from Sun Pharmaceutical Ltd., Vadodara, India. Sodium

This is an open access article distributed under the terms of the Creative Commons Attribution-NonCommercial-ShareAlike 3.0 License, which allows others to remix, tweak, and build upon the work non-commercially, as long as the author is credited and the new creations are licensed under the identical terms

Accepted 20 March 2017

Revised 27 December 2016

Received 04 August 2016

Indian J Pharm Sci 2017;79(2):277-286 


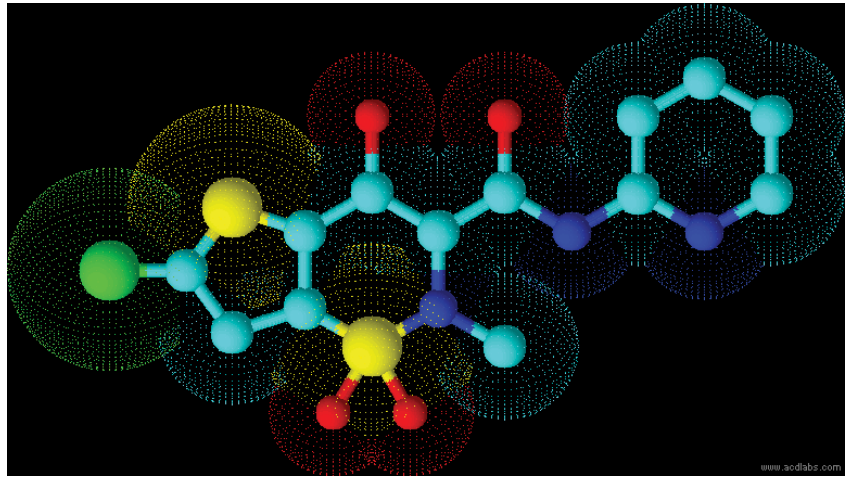

Fig. 1: Lornoxicam chemical structure

saccharin and all other coformers were procured from Research Fine Lab., Mumbai. All other materials used in the study were of analytical grade. A digital melting point apparatus (Chief Scientific), Roche friability test apparatus (VFT-2D, Veego Instruments Corp.), dissolution test apparatus (VDA6DR, Veego Instruments Corp.), ultraviolet spectrophotometer (UV1800, Shimadzu), Fourier transform spectrophotometer (Thermo Fischer Scientific), differential scanning calorimeter (DSC, Mettler Toledo), powder X-ray diffractometer (Panalytical's X'Pert Pro) and FTRaman spectrometer (Bruker RFS 27) were utilized for characterization of raw materials and the evaluation of formulations under study. The tablet compression machine (Karnavati Engineering), was used for direct compression of tablets.

\section{Preparation and evaluation of cocrystals:}

Lornoxicam cocrystals were prepared using the API and coformer in 1:1 $\mathrm{M}$ stoichiometric ratio by neat grinding method. The mixtures were then ground for $20 \mathrm{~min}$ in an agate mortar with a pestle. The milling time was kept short to avoid any degradation of the materials ${ }^{[18,19]}$. The melting point of raw materials and cocrystals were determined by the capillary method. In this methodology, a thin glass capillary tube containing the substance to be determined was introduced into a heated stand (liquid paraffin) in close proximity to a high accuracy thermometer. The temperature in the heating stand was raised at a fixed rate until the sample in the tube transitioned into the liquid state ${ }^{[19]}$. Drug content was estimated by dissolving weighed quantities of cocrystals in $5 \% \mathrm{w} / \mathrm{v}$ aqueous $\mathrm{N}, \mathrm{N}-$ dimethylformamide in triplicate. The solutions were filtered and diluted appropriately and samples were analysed spectrophotometrically at $\lambda_{\text {max }} 378 \mathrm{~nm}$.

Shake flask method was employed for the aqueous solubility measurements, performed in triplicates by
Higuchi and Connors method ${ }^{[20]}$. An excess amount of cocrystals were added to the flask containing distilled water. The solutions were vortexed for $2 \mathrm{~min}$ and placed on a rotary shaker at $100 \mathrm{rpm}$ and $27 \pm 0.5^{\circ}$ for 24 h. After equilibrium, the solution was filtered through Whatman filter paper (\#41) and the concentration of drug was determined spectrophotometrically at $\lambda_{\text {max }}$ $378 \mathrm{~nm}^{[21]}$.

The prepared cocrystals were evaluated for various flow property parameters like bulk density (BD), tapped density (TD), Carr's index (CI), Hausner's ratio (HR) and the angle of repose (AR). AR was measured using the fixed funnel method ${ }^{[22]}$. The partition coefficient of the API and lornoxicam-saccharin sodium cocrystals were determined in octanol/water and octanol/ phosphate buffer $\mathrm{pH} 7.4$ systems. The study was performed in triplicate ${ }^{[23]}$.

The FTIR spectra of lornoxicam and optimized batch of cocrystals were obtained on the FTIR using the $\mathrm{KBr}$ disk method and the scanning range was in between $4000-660 \mathrm{~cm}^{-124]}$. Raman spectroscopic analysis is a spectroscopic technique used to study vibrational, rotational and other low frequency modes in a system, which has been demonstrated to be a powerful tool for distinguishing is the structural phase. There are many applications using Raman spectroscopy to identify characteristic peaks of cocrystal products. The analysis of optimized cocrystals was performed using FTRaman spectrometer ${ }^{[25]}$.

Powder XRD pattern of lornoxicam and optimized batch of cocrystals were recorded using powder $\mathrm{X}$-ray diffractometer and using $\mathrm{Cu}-\mathrm{k} \alpha$ radiation. The diffractometer was run at a scanning speed of $2 \% / \mathrm{min}$ and a chart speed of $2 \% / 2 \mathrm{~cm}$ per $2 \theta$. DSC of lornoxicam and optimized batch of cocrystals were done using $\mathrm{DSC}$, at a heating rate of $10^{\circ} \mathrm{min}$ in the range $50^{\circ}$ to $300^{\circ}$ under the nitrogen atmosphere ${ }^{[26]}$.

\section{Formulation and evaluation of tablets:}

Conventional immediate release tablets of lornoxicamsaccharin sodium cocrystals were prepared by direct compression technique. The batches were prepared by $2^{2}$ factorial experimental designs ${ }^{[19]}$. Formulae for 4 experimental batches were given in Table 1 . The prepared tablets of cocrystals were evaluated for uniformity of weight, hardness and friability. The hardness was determined by using Veego hardness tester, where the force required to break the tablet was noted. Uniformity of weight was determined by 
weighing 20 tablets individually and calculating the average weight and comparing the individual tablet weight to the average value. The friability of the tablets was determined using Veego friabilator ${ }^{[27]}$.

\section{In vitro dissolution studies:}

In vitro dissolution studies of tablets was performed using USP apparatus type II (Veego) fitted with the paddle (50 rpm) at $37 \pm 0.5^{\circ}$ using phosphate buffer $\mathrm{pH}$ 7.4 , and water $900 \mathrm{ml}$ as a dissolution medium. Aliquot of $5 \mathrm{ml}$ samples were withdrawn, at an interval of every $10 \mathrm{~min}$ to $60 \mathrm{~min}$. The samples were filtered and assayed at $\lambda_{\max } 378 \mathrm{~nm}$ using a UV 1800 double-beam spectrophotometer (Shimadzu). At each time point, after withdrawing the sample, an equal volume was replaced with fresh dissolution media. Prepared tablets of optimized cocrystals were compared with marketed product in terms of in vitro drug release study ${ }^{[28]}$.

\section{Stability studies:}

Optimized formulation was subjected to stability studies at temperature $40^{\circ} / 75 \%$ relative humidity $(\mathrm{RH})$ for a period of $1 \mathrm{mo}$. The optimized formulation sealed in aluminium foil was kept at the above mentioned temperature and humidity condition ${ }^{[29]}$. At the end of studies, samples were analysed for appearance, drug release in phosphate buffer $\mathrm{pH} 7.4$, percent drug content, hardness and friability. Results of drug content and drug release studies of tablets under stability studies were analysed using the student's t-test ${ }^{[30]}$.

\section{RESULTS AND DISCUSSION}

The melting point of API, coformers and cocrystals were as given in Table 2. Almost in all cocrystal batches melting point was different from API and coformers. There was no correlation between melting point of cocrystal and API/coformer. The transformed melting points of cocrystals may be assigned to the physical non-covalent interaction between drug and coformer, altered packing arrangement or change in the crystallinity of molecules ${ }^{[31]}$.

The data for aqueous solubility profile of the API was shown in fig. 2 . The solubility of cocrystals in

TABLE 1: EXPERIMENTAL BATCHES

\begin{tabular}{lcccc}
\hline Ingredients & P1 $\mathbf{( g )}$ & P2 $\mathbf{( g )}$ & P3 $(\mathbf{g})$ & P4 $(\mathbf{g})$ \\
\hline Lornoxicam-sodium saccharin cocrystal & 13.27 & 13.27 & 13.27 & 13.27 \\
Microcrystalline cellulose PH 101 & 180.73 & 166.73 & 178.73 & 168.73 \\
Magnesium stearate & 2.0 & 4.0 & 4.0 & 2.0 \\
Sodium starch glycolate & 4.0 & 16.0 & 4.0 & 16.0 \\
Total weight & 200.00 & 200.00 & 200.00 & 200.00 \\
\hline
\end{tabular}

TABLE 2: SOLUBILITY AND MELTING POINT OF COCRYSTALS

\begin{tabular}{|c|c|c|c|c|}
\hline Formulation & Drug/coformer & $\begin{array}{c}\text { MP of drug/coformers } \\
\left({ }^{\circ}\right)\end{array}$ & $\begin{array}{c}\text { MP of cocrystals } \\
\left({ }^{\circ}\right)\end{array}$ & $\begin{array}{c}\text { Average solubility API/ } \\
\text { cocrystal }(\mu \mathrm{g} / \mathrm{ml})\end{array}$ \\
\hline F1 & Lornoxicam & $225-230$ & - & $22.690 \pm 2.05$ \\
\hline $\mathrm{F} 2$ & Benzoic acid & 122.4 & 228 & $22.95 \pm 3.33$ \\
\hline F3 & Salicylic acid & 157-159 & $185-190$ & $11.10 \pm 2.33$ \\
\hline F4 & Malonic acid & 135 & $280-285$ & $26.35 \pm 1.13$ \\
\hline F5 & 4-Hydroxy Benzoic acid & $213-214$ & $180-185$ & $60.05 \pm 3.66$ \\
\hline F6 & Succinic acid & $185-187$ & $260-265$ & $25.33 \pm 1.50$ \\
\hline F7 & Tartaric acid & $168-170$ & $193-196$ & $21.87 \pm 2.00$ \\
\hline F8 & Fumaric acid & 287 & $270-275$ & $14.04 \pm 2.39$ \\
\hline F9 & Anthranillic acid & $146-148$ & $220-222$ & $36.47 \pm 1.69$ \\
\hline F10 & Ascorbic acid & $190-192$ & $255-260$ & $21.38 \pm 3.25$ \\
\hline F11 & Cinnamic acid & 133 & $250-255$ & $25.23 \pm 3.88$ \\
\hline F12 & PABA & $187-187.5$ & $223-225$ & $64.12 \pm 1.33$ \\
\hline F13 & Hippuric acid & 187-188 & $265-268$ & $10.88 \pm 1.04$ \\
\hline F14 & Ferulic acid & 174 & $190-195$ & $71.04 \pm 2.44$ \\
\hline F15 & Glutaric acid & $95-98$ & $220-225$ & $17.04 \pm 1.25$ \\
\hline F16 & Urea & $133-135$ & $235-240$ & $55.09 \pm 1.66$ \\
\hline F17 & Resorcinol & $109-111$ & $245-250$ & $47.89 \pm 2.30$ \\
\hline F18 & Saccharin sodium & $>300$ & $245-250$ & $156.05 \pm 1.33$ \\
\hline F19 & Citric acid & 150 & $195-200$ & $23.55 \pm 1.69$ \\
\hline F20 & Oxalic acid & 101 & $200-205$ & $43.06 \pm 1.06$ \\
\hline
\end{tabular}


distilled water was shown in Table 2. The maximum aqueous solubility was obtained with lornoxicamsaccharin sodium cocrystals (F18), which might have resulted from changes in the molecular attributes due to non-covalent interaction in cocrystals. Saccharin has been reported as typical coformer in the literature for improving solubility of the parent API and also to make sweet cocrystal owing its sweetening property ${ }^{[32,33]}$. The more hydrophilic nature of coformer as compared to the constituent drugs, and therefore such selective drug solubilisation is generally observed with solubilizing agents (coformer) in aqueous media ${ }^{[34]}$. Solubility is related to the crystal lattice energy within the solid state; there are various potential interactions within the crystal structure including hydrogen bonding and vander Waals interactions within cocrystals ${ }^{[35]}$. The solubility enhancement of lornoxicam in cocrystals with saccharin may be a result of lower lattice energy of cocrystals allowing the more facile crystal disruption by the solvent ${ }^{[36]}$. The solubility advantage of cocrystals could effectively translate to an improved absorption of the drug.

The BD and TD, the AR, CI, and HR were measured and presented in Table 3. It was observed that parameters indicating flow characteristics were significantly improved with lornoxicam-saccharin sodium cocrystals as compared to API. This result emphasized altered packing arrangement in cocrystal leading to improved micromeritic properties.

The partition coefficient $(\log \mathrm{P})$ of lornoxicam in octanol/water and octanol/buffer $\mathrm{pH} 7.4$ was 2.13 and 1.91, respectively. It indicated that lornoxicam is hydrophobic in nature, which might be the reason for its poor aqueous solubility. The reported partition

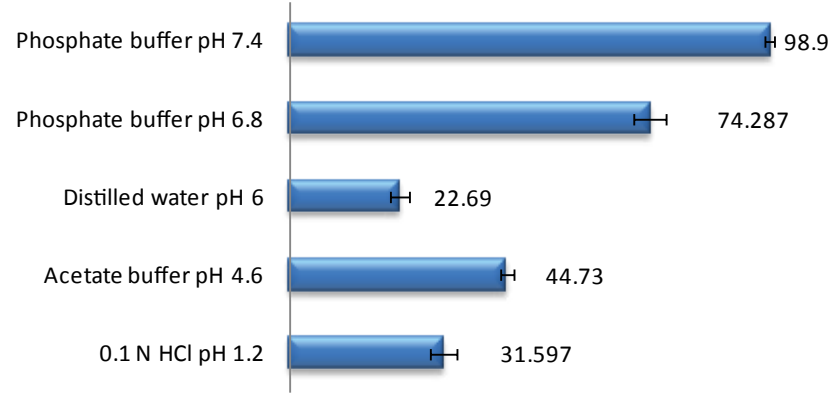

Fig. 2: pH solubility profile of lornoxicam

- - Solubility $(\mu \mathrm{g} / \mathrm{ml})$ coefficient of lornoxicam is 1.8 , as determined in n-octanol and phosphate buffer $(\mathrm{pH} \text { 7.4 })^{[37]}$. The partition coefficient $(\log \mathrm{P})$ of lornoxicam:saccharin sodium cocrystals was found to be 1.69 and 1.28 , respectively in octanol/water and octanol/buffer $\mathrm{pH}$ 7.4 systems. This revealed the transformation of hydrophobic nature of lornoxicam to hydrophilic nature in cocrystal form.

FTIR is an important tool for prediction of cocrystal formation and it showed the hydrogen bond formation between API and the coformer. Important peaks seen were at $-\mathrm{OH}$ stretching, $3671.8 \mathrm{~cm}^{-1}$, -NH stretching aromatic, $3467.38 \mathrm{~cm}^{-1},-\mathrm{C}=\mathrm{O}$ ketone stretching, $1681.62 \mathrm{~cm}^{-1}, \mathrm{~S}=\mathrm{O}$ symmetric stretching, 1187.94 $\mathrm{cm}^{-1}, \mathrm{~S}=\mathrm{O}$ asymmetric stretching, $1342.21 \mathrm{~cm}^{-1}$, aromatic C-H stretching, $2938.98 \mathrm{~cm}^{-1}$, -Cl stretching, $794.52 \mathrm{~cm}^{-1[38]}$. FTIR spectra of API, coformer and cocrystal were given in fig. 3 . The alteration in peak shape at $3671.8 \mathrm{~cm}^{-1}$ and broadening at $2950.55 \mathrm{~cm}^{-1}$ indicated conjugation of the hydroxyl group with the aromatic alkyl function in lornoxicam, which might be assigned to non-covalent interaction in cocrystal. Weak interaction seen at $3467.38 \mathrm{~cm}^{-1}$ indicated the involvement of the secondary amine in lornoxicam.

Raman spectroscopy has also been an imperative tool for predicting cocrystal formation demonstrating the hydrogen bond formation between the API and CCF. FT-Raman spectrum of the cocrystal was shown in fig. 4 . Important peaks seen were $\mathrm{C}=\mathrm{N}$ strong $1590.04 \mathrm{~cm}^{-1}$, $\mathrm{C}=\mathrm{O}$ medium $1635.83 \mathrm{~cm}^{-1}, \mathrm{C}-\mathrm{S}$ aromatic 1179.83 $\mathrm{cm}^{-1}, \mathrm{CH}_{3}$ medium $1382.81 \mathrm{~cm}^{-1}, \mathrm{Cl}$ strong 690.42 $\mathrm{cm}^{-1}$. The characteristics peaks of $(\mathrm{O}-\mathrm{H})$ at $3100-3650$ $\mathrm{cm}^{-1}$ and $(\mathrm{N}-\mathrm{H})$ at $3300-3500 \mathrm{~cm}^{-1}$ were not observed in FT-Raman spectra indicated weak non-covalent bond formation. XRD patterns of drug and cocrystals were shown in fig. 5. The diffraction pattern of the API and cocrystals showed that both were crystalline in nature as demonstrated by numerous distinct peaks of 20. Powder XRD pattern of lornoxicam cocrystals indicates formation of new crystalline phases, which can be attributed to cocrystal formation ${ }^{[39,40]}$.

DSC analysis was employed to evaluate the phase of transformation during the formation of cocrystals. DSC thermogram of lornoxicam in fig. 6A showed an endothermic peak at $221.26^{\circ}$ corresponding to its

TABLE 3: PRE-FORMULATION CHARACTERISTICS OF API AND COCRYSTAL

\begin{tabular}{lccccc}
\hline API/cocrystal & Angle of repose $\left({ }^{\circ}\right)^{*}$ & Bulk density $(\mathrm{gm} / \mathrm{ml})^{*}$ & ${\text { Tapped density }(\mathrm{gm} / \mathrm{ml})^{*}}$ Carr's index (\%) $^{*}$ Hausner's ratio* $^{*}$ \\
\hline API & $41.66 \pm 2.99$ & $0.30 \pm 0.02$ & $0.52 \pm 0.06$ & $42.40 \pm 1.29$ & $1.73 \pm 0.06$ \\
Cocrystal & $26.72 \pm 1.05$ & $0.73 \pm 0.05$ & $0.91 \pm 0.04$ & $19.78 \pm 1.12$ & $1.24 \pm 0.02$ \\
\hline
\end{tabular}

${ }^{*}$ Mean \pm SD, $n=3$ 


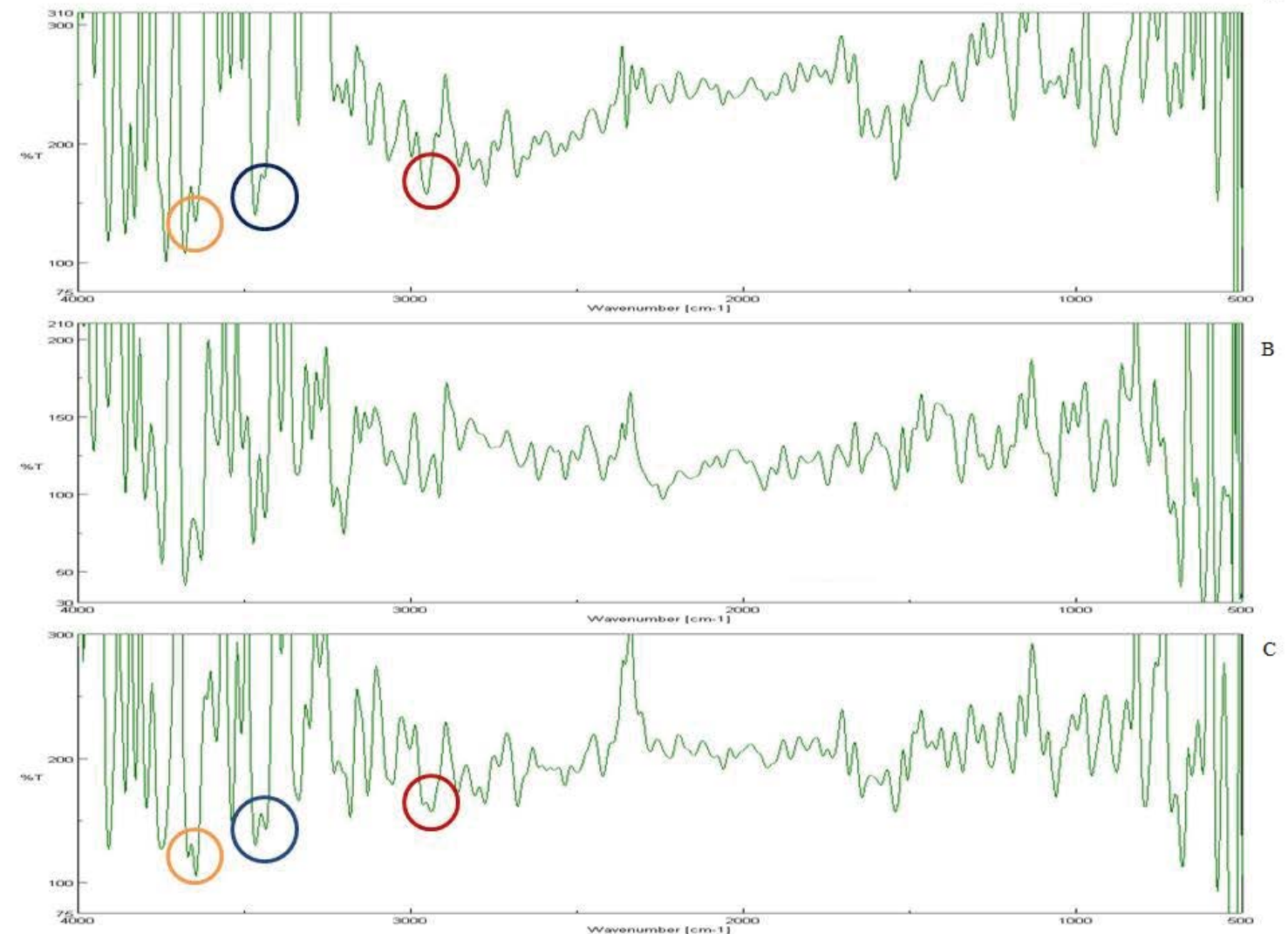

Fig. 3: FTIR spectrum of API, CCF and cocrystal

A. Lornoxicam; B. saccharin; C. lornoxicam-saccharin cocrystal

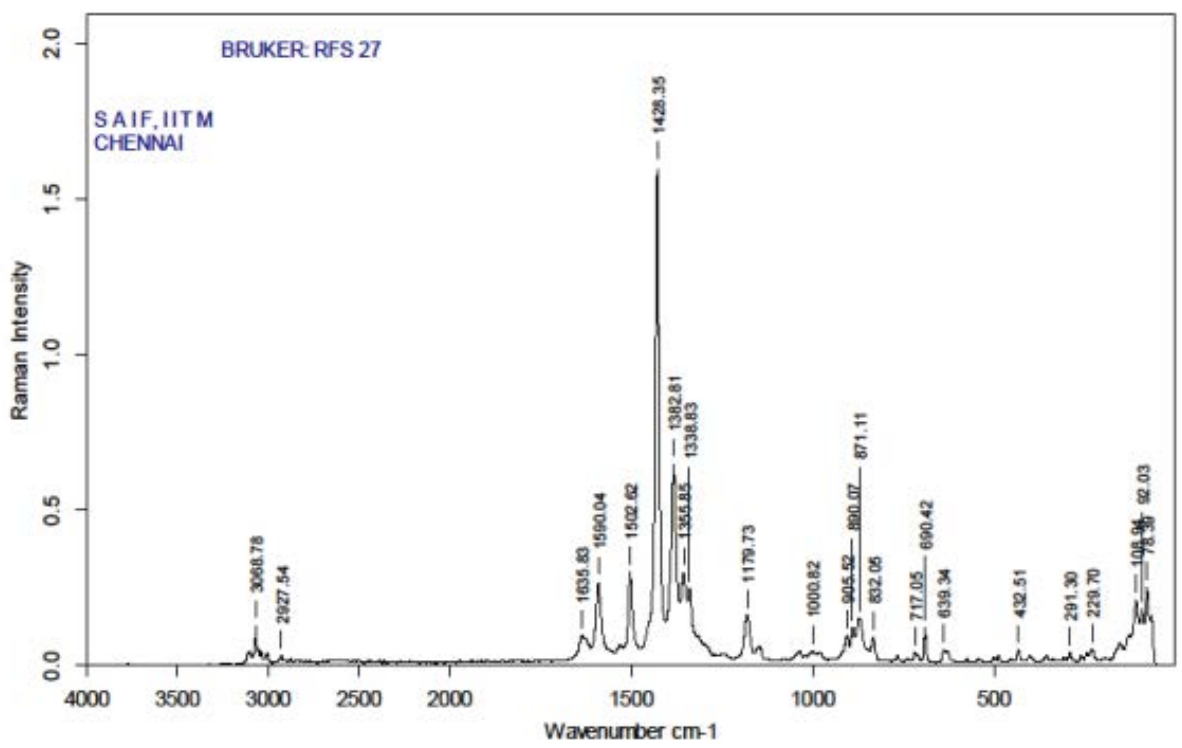

Fig. 4: Raman spectra of lornoxicam cocrystals

melting point. There was a shift in the drug peak in case of the cocrystals and a single peak was observed at $219.28^{\circ}$ in fig. $6 \mathrm{~B}$. The strong non-covalent interaction between the API and the coformer generally led to the formation of cocrystals. This non-covalent physical interaction expected to be between an API and a coformer is due to hydrogen bond formation between polar functional groups. This interaction resulted in moderate to complete alterations in molecular arrangement of cocrystal formed, thus giving a new crystalline arrangement with altered physical properties including the melting point and/or the solubility. The 


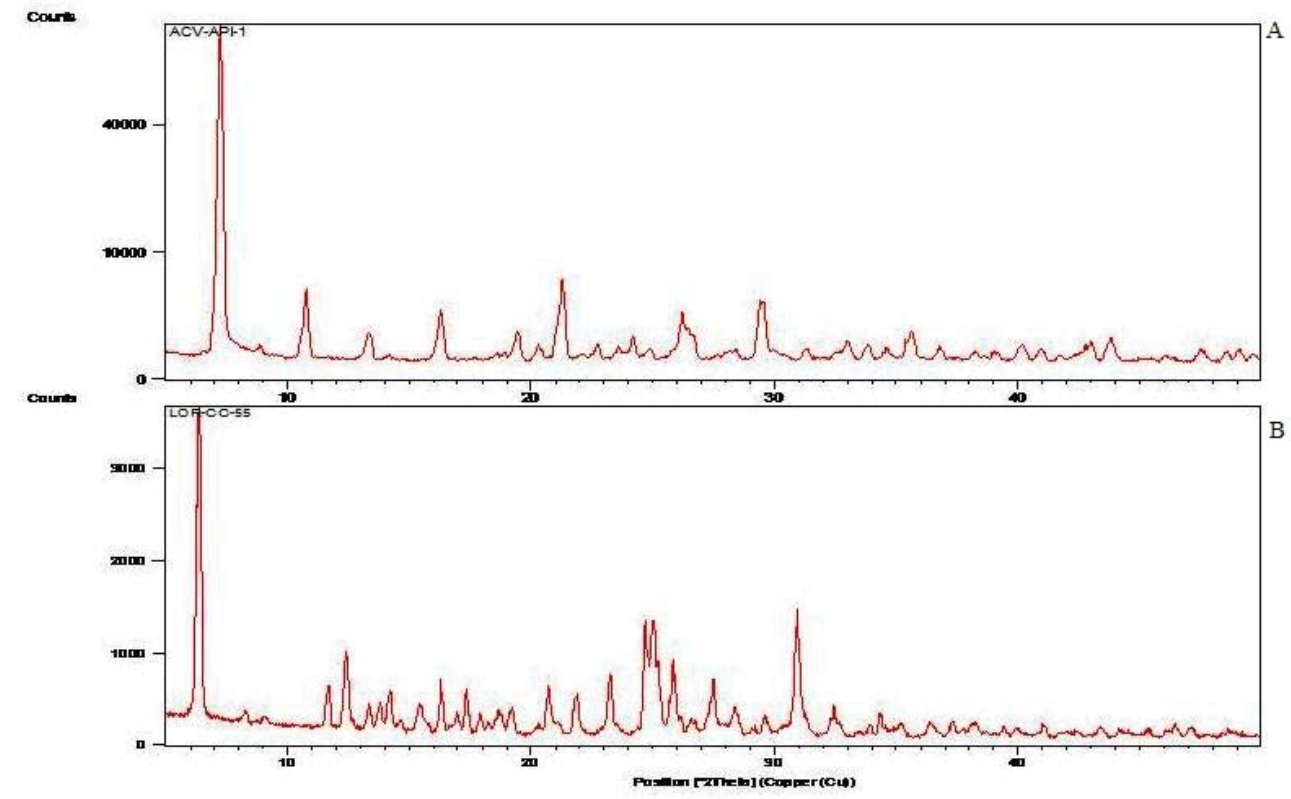

Fig. 5: Powder X-ray diffractogram of lornoxicam (A) and lornoxicam-saccharin sodium cocrystal, 1:1 (B)

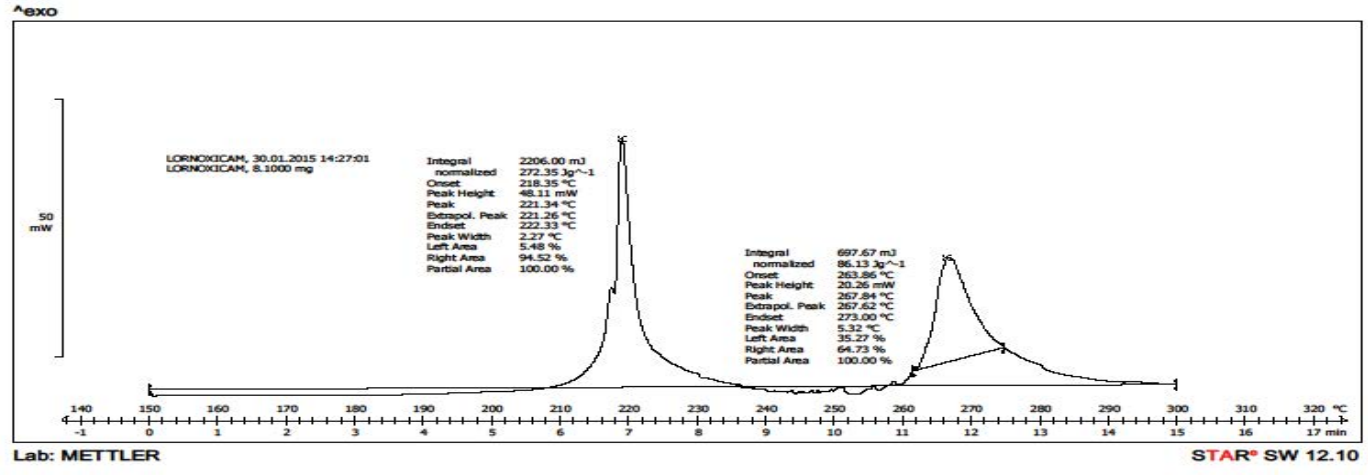

A.

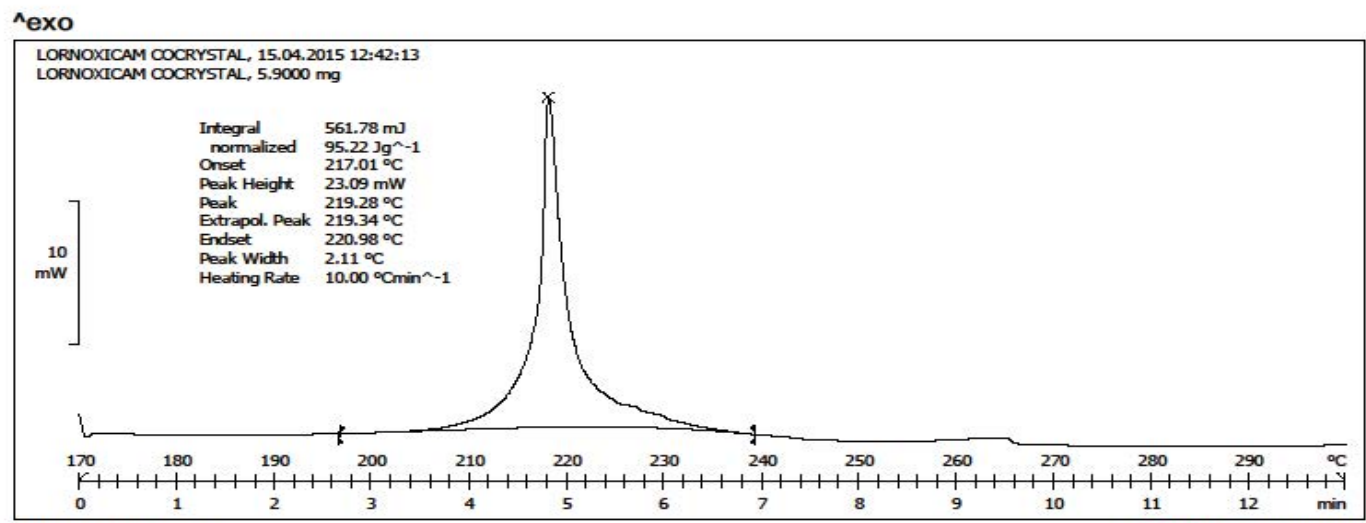

B.

Lab: METTLER STAR $^{\circ}$ SW 12.10

Fig. 6: DSC thermograms of lornoxicam (A); lornoxicam-sodium saccharin cocrystals (B)

formation of cocrystal was also confirmed on the basis of powder XRD studies, which indicated completely different diffractograms for cocrystals and lornoxicam. Thus the strength of hydrogen bonding will definitely influence the melting point characteristic of a cocrysta ${ }^{[41]}$.

The evaluation results of immediate release tablet of lornoxicam cocrystal are shown in Table 4. The hardness of P4 batch was found to be $5.5 \pm 0.5 \mathrm{~kg} /$ $\mathrm{cm}^{2}$. Uniformity of weight and friability were 
found to be within pharmacopoeia limits ${ }^{[42]}$. In vitro disintegration time was found to be not more than 24 $\mathrm{s}$. The intrinsic dissolution rate (IDR) at the end of $60 \mathrm{~min}$ was $10.81 \pm 0.17 \mathrm{mg} / \mathrm{cm}^{2}$ and $12.73 \pm 0.26 \mathrm{mg} /$ $\mathrm{cm}^{2}$, respectively for lornoxicam and F18 cocrystal indicating cocrystal improved IDR. After performing the evaluation of experimental formulation batches $86.14 \pm 1.33 \%$ and $93.01 \pm 0.77 \%$ cumulative drug release was observed in distilled water and phosphate buffer $\mathrm{pH} 7.4$, respectively with $\mathrm{P} 4$ batch. Hence, it was selected as optimized batch.

The optimized formulation was compared with marketed tablets in the in vitro dissolution study in distilled water and phosphate buffer $\mathrm{pH} 7.4$ shown in figs. 7 and 8, respectively. Percent cumulative drug release was found to be $47.63 \pm 0.51 \%$ and $57.93 \pm 1.66 \%$ at the end of $60 \mathrm{~min}$, respectively in distilled water and phosphate buffer $\mathrm{pH} 7.4$ with marketed tablets (Lofecam, Sun Pharma). The percent cumulative drug release at the end of 60 min with $\mathrm{P} 4$ batch was $86.14 \pm 1.33 \%$ and $93.01 \pm 0.77 \%$ indicating improved dissolution of lornoxicam by co-crystallization.

The $2^{2}$ experimental factorial design was used in this study for optimization of variables magnesium stearate (A) and sodium starch glycolate (B) (SSG) for preparation of immediate release tablet formulations of lornoxicam: saccharin sodium cocrystal. The magnesium stearate was evaluated at $1 \% \mathrm{w} / \mathrm{w}$ and $2 \% \mathrm{w} / \mathrm{w}$ and SSG was evaluated at $2 \% \mathrm{w} / \mathrm{w}$ and $8 \%$ $\mathrm{w} / \mathrm{w}$ concentration in the experimental design at -1 and +1 levels, respectively. There was minimal effect of magnesium stearate on drug dissolution but SSG can improve dissolution to a certain extent as it can be seen from the Eqns. given below and contour surface plots in fig. 9.

The response-drug release of lornoxicam from the immediate release tablets of cocrystal was determined at the end of $60 \mathrm{~min}$ in distilled water and phosphate buffer $\mathrm{pH}$ 7.4. The coded and uncoded Eqns. for the drug release were obtained from SPC package for MS-Excel and were as given below. Eqns for drug release in distilled water were coded: $\% \mathrm{DR}=82.140$ $0.642 \mathrm{~A}+1.595 \mathrm{~B}-1.720 \mathrm{AB}$ and Uncoded: \%DR $=72.81+4.450 \times$ magnesium stearate $+1.595 \times \mathrm{SSG}-$ $1.720 \times$ magnesium stearate $\times$ SSG. Eqns. for drug release in phosphate buffer $\mathrm{pH} 7.4$ were, coded: $\% \mathrm{DR}=$ 87.249-0.744 A+3.363-1.461 AB and uncoded: \%DR $=76.57+3.381 \times$ magnesium stearate $+2.582 \times \mathrm{SSG}-$ $0.974 \times$ magnesium stearate $\times \mathrm{SSG}$, where, $\% \mathrm{DR}$ is percent cumulative drug release, (A) is magnesium stearate and (B) is SSG.

The addition of SSG can improve drug release while addition of magnesium stearate could decrease the drug release from formulation. SSG is hydrophilic

\section{TABLE 4: EVALUATION OF ALL BATCHES}

\begin{tabular}{lccccc}
\hline Batch & $\begin{array}{c}\text { Thickness }(\mathrm{mm})^{*} \\
(\mathbf{n}=3)\end{array}$ & $\begin{array}{c}\text { Hardness }(\mathbf{k g} / \\
\left.\mathbf{c m}^{2}\right)^{*}(\mathbf{n = 3})\end{array}$ & $\begin{array}{c}\text { In vitro disintegration time } \\
(\mathbf{m i n})^{*}(\mathbf{n = 3})\end{array}$ & $\begin{array}{c}\text { Uniformity of weight } \\
(\mathbf{g})^{*}(\mathbf{n = 2 0})\end{array}$ & $\begin{array}{c}\text { Friability }(\%)^{*} \\
(\mathbf{n}=35)\end{array}$ \\
\hline P1 & $3.18 \pm 0.03$ & $5.8 \pm 0.4$ & $20 \pm 4$ & $0.20 \pm 0.002$ & $0.76 \pm 0.30$ \\
P2 & $3.20 \pm 0.02$ & $5.6 \pm 0.2$ & $18 \pm 2$ & $0.20 \pm 0.003$ & $0.66 \pm 0.31$ \\
P3 & $3.21 \pm 0.03$ & $5.5 \pm 0.4$ & $21 \pm 1$ & $0.20 \pm 0.003$ & $0.79 \pm 0.20$ \\
P4 & $3.19 \pm 0.05$ & $5.5 \pm 0.5$ & $20 \pm 2$ & $0.20 \pm 0.002$ & $0.66 \pm 0.23$ \\
\hline
\end{tabular}

${ }^{*}$ Mean \pm SD

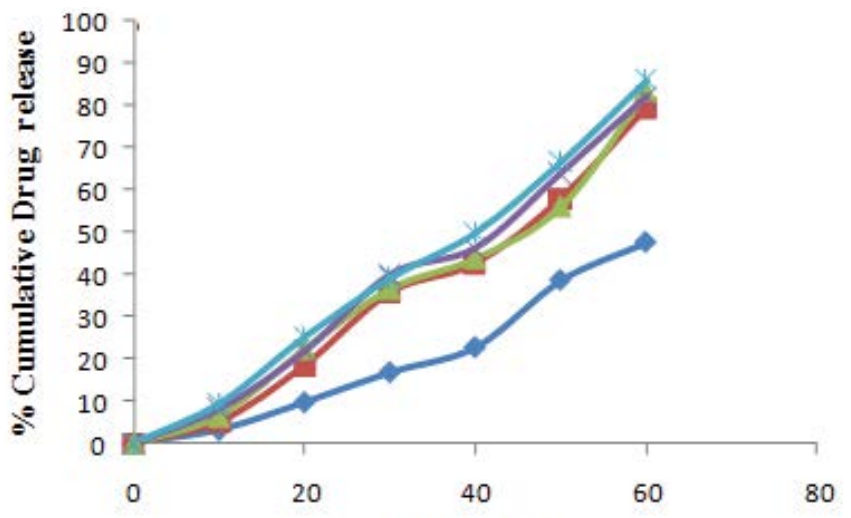

Time (min)

Fig. 7: Percent Cumulative Drug release of P1 to P4 batches and marketed tablet (Lofecam) in distilled water $-\downarrow$ MT; - - P1; $-\triangle-$ P2; $-\times-$ P3; $-{ }^{*}-$ P4

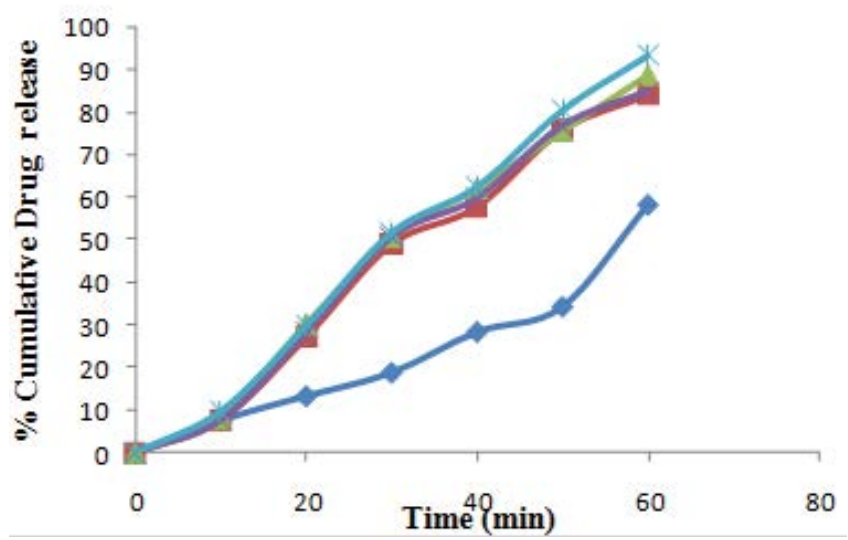

Fig. 8: Percent cumulative drug release of $P 1$ to $P 4$ batches and marketed tablet (Lofecam) in buffer $\mathrm{pH} 7.4$

$-\uparrow$ MT; - - P1; - $\triangle-$ P2; - - P3; - *-P4 
carboxymethylated starch polymer, which act by rapid water uptake and its water uptake is higher at alkaline $\mathrm{pH}$ compared to acidic $\mathrm{pH}^{[43]}$. SSG takes up more than 20 times its own weight of water ${ }^{[44]}$. Hence, it showed faster swelling and disintegration of tablet assisting dissolution of the drug. Magnesium stearate is hydrophobic lubricant commonly used in small concentration but increasing its concentration in the formulation could decrease the drug release. The P-values for the percent cumulative drug release of lornoxicam:saccharin sodium co-crystals in distilled water and phosphate buffer at $\mathrm{pH} 7.4$ were less than 0.05 . Thus, the $2^{2}$ experimental factorial designs can be utilized for evaluation effects of selected variables magnesium stearate and SSG on drug release. The factorial interactions of variables were diminishing

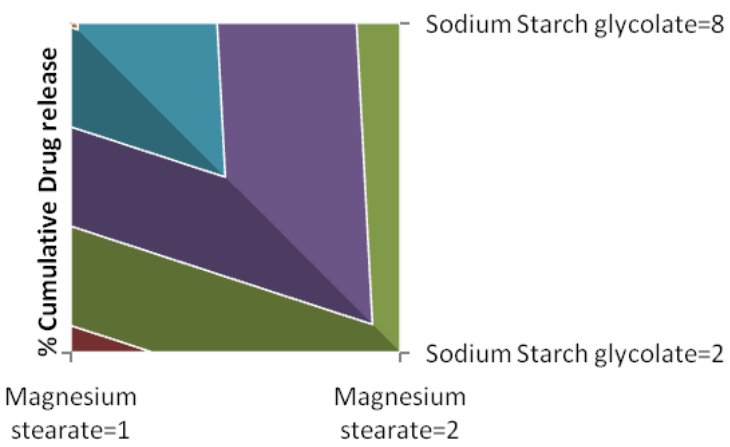

A.

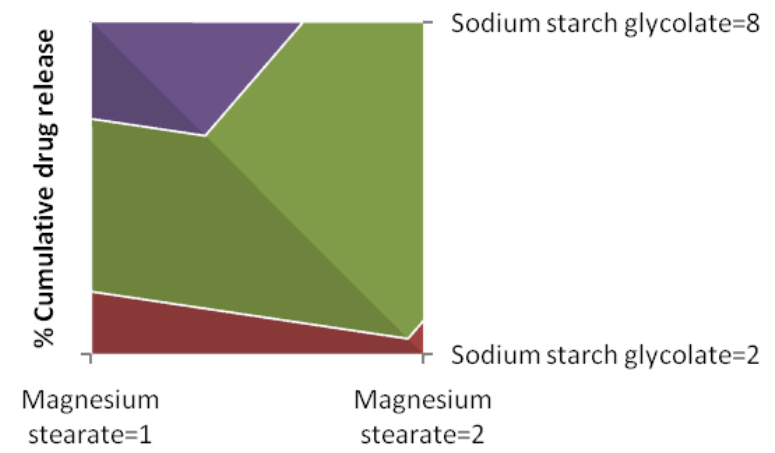

Fig. 9: Contour surface plot for $2^{2}$ factorial design for dissolution profile in distilled water (A); phosphate buffer pH 7.4 (B)

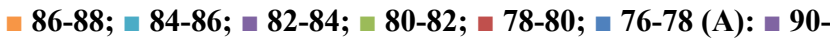
95; $\approx$ 85-90; $\approx$ 80-85; $\square$ 75-80 (B) the drug release of lornoxicam from formulation as exemplified in equations. Hence, concentration of magnesium stearate shall be kept low while SSG can be used at higher concentration to obtain optimum drug release from the tablet formulations.

The drug content, hardness, friability and disintegration time of $\mathrm{P} 4$ batch of tablet formulation was evaluated during stability studies. The outcomes of stability studies for P4 batch were as reported in Table 5. It reveals that the optimized formulation was quite stable at room temperature. The data of drug content and drug release in $\mathrm{pH} 7.4$ buffer (at the end of $60 \mathrm{~min}$ ) for P4-batch during stability studies was evaluated by Paired student's t test using GraphPad Prism 5.0. There was no significant difference in drug content and percent cumulative drug release (fig. 10) of P4batch formulation at $25 \pm 2^{\circ}$ and $\mathrm{RH} 60 \pm 5 \%$ at the end of $30 \mathrm{~d}$. The drug content and drug release (at the end of $60 \mathrm{~min}$ ) in phosphate buffer for $\mathrm{P} 4$ formulation batch at accelerated condition $40^{\circ} \pm 2$ and $\mathrm{RH} 75 \pm 5 \%$ shows the significant difference at the end of $30 \mathrm{~d}$ as evaluated by student's t-test. Therefore, P4-batch of tablet formulation was found to be quite stable at room temperature than the accelerated condition.

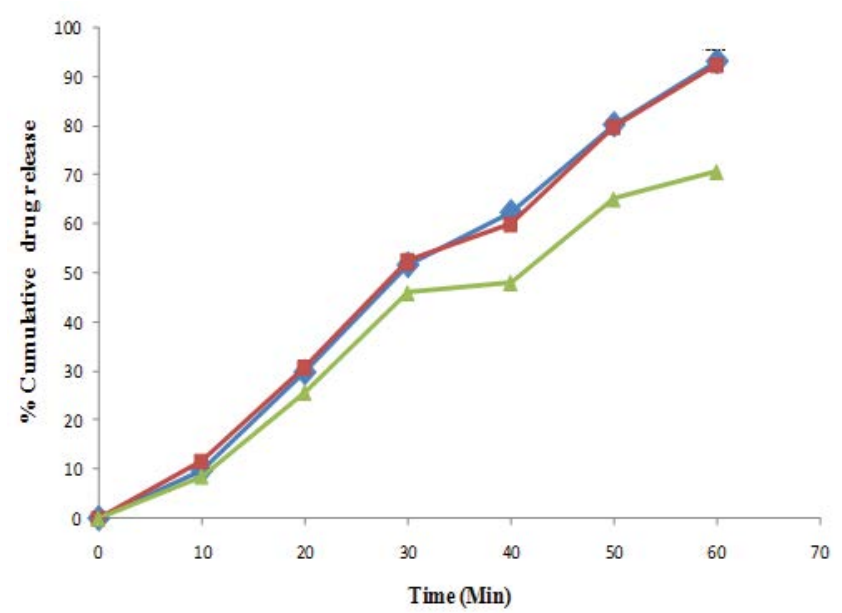

Fig. 10: Percent cumulative drug release of $P 4$ batch tablets in phosphate buffer at pH 7.4 during stability studies

- - Initial drug release; - - - after $30 \mathrm{~d}$ at $25^{\circ}$; $-\Delta-$ after $30 \mathrm{~d}$ at accelerated conditions

TABLE 5: STABILITY DATA OF TABLET FORMULATION BATCH P4

\begin{tabular}{lccccc}
\hline Parameters & Appearance & $\begin{array}{c}\text { Drug content }(\%)^{*} \\
\text { Initial } 25^{\circ} \pm 2^{\circ}\end{array}$ & $\begin{array}{c}\text { In vitro disintegration } \\
\text { time }(\mathrm{min})^{*}\end{array}$ & $\begin{array}{c}\text { Hardness }(\mathrm{kg} / \\
\left.\mathrm{cm}^{2}\right)^{*}\end{array}$ & Friability $(\%)^{*}$ \\
\hline $40 \pm 2^{\circ} / \mathrm{RH} 75 \pm 5 \%$ & Yellow & $99.77 \pm 0.15$ & $21 \pm 1.5$ & $5.5 \pm 0.4$ & $0.62 \pm 0.39$ \\
$25 \pm 2^{\circ} / \mathrm{RH} 60 \pm 5 \%$ & Yellow & $99.35 \pm 0.33$ & $20 \pm 2.3$ & $5.1 \pm 0.5$ & $0.58 \pm 0.23$ \\
& Yellow & $98.95 \pm 0.65$ & $20 \pm 2.5$ & $5.2 \pm 0.3$ & $0.60 \pm 0.09$ \\
\hline $40 \pm 2^{\circ} / \mathrm{RH} 75 \pm 5 \%$ & After 30 d & & & \\
$25 \pm 2^{\circ} / \mathrm{RH} 60 \pm 5 \%$ & Yellow & $98.52 \pm 1.05$ & $20 \pm 2.5$ & $5.0 \pm 0.6$ & $0.56 \pm 0.43$ \\
\hline
\end{tabular}

${ }^{*} M e a n \pm S D, n=3$ 
The major problem associated with lornoxicam was its low solubility and there by high variability in bioavailability after oral administration. Therefore, it was necessary to enhance the solubility and dissolution rate of lornoxicam to obtain faster dissolution. This was achieved by formulating cocrystals of API by neat grinding method. Maximum solubility was obtained with saccharin sodium as a cocrystal former (1:1 stoichiometric ratio) along with improved dissolution rate. From the above discussion, it is clear that improvement in solubility and dissolution rate of lornoxicam can be achieved by cocrystals. In vitro dissolution of optimized lornoxicam cocrystal tablet was comparatively higher than API and marketed formulation, which reflect improvement in solubility. Thus, the corystals can work as an antique and multifaceted approach for improvement of solubility and dissolution with improvement in physicochemical properties of poorly water soluble drugs ${ }^{[45]}$ like lornoxicam. From the current study, it was concluded that stable cocrystals of lornoxicam with saccharin sodium can be successfully prepared by crystal engineering approach with improved solubility and in vitro dissolution.

\section{Acknowledgements:}

Authors thank the Sun Pharmaceuticals Ltd., Ahmedabad, India for providing drug as a gift sample.

\section{Conflict of interest:}

The author (s) declares no conflict of interest.

\section{Financial support and sponsorship:}

Nil.

\section{REFERENCES}

1. Savjani KT, Gajjar AK, Savjani JK. Drug solubility: importance and enhancement techniques. ISRN Pharm 2012;2012:1-10.

2. Rasenack N, Müller BW. Dissolution rate enhancement by in situ micronization of poorly water-soluble drugs. Pharm Res 2002;19:1894-900

3. Rawat S, Jain SK. Solubility enhancement of celecoxib using $\beta$-cyclodextrin inclusion complexes. Eur J Pharm Biopharm 2004;57:263-7.

4. Modi A, Tayade P. A comparative solubility enhancement profile of valdecoxib with different solubilization approaches. Indian J Pharm Sci 2007;69:274-8.

5. Chaudhari P, Sharma P, Barhate N, Kulkarni P, Mistry C. Solubility enhancement of hydrophobic drugs using synergistically interacting cyclodextrins and cosolvent. Curr Sci 2007;92:1586-91
6. Dehghan $\mathrm{MH}$, Jafar M. Improving dissolution of meloxicam using solid dispersions. Iranian J Pharm Res 2010;20:231-8.

7. Sanphui P, Tothadi S, Ganguly S, Desiraju GR. Salt and cocrystals of sildenafil with dicarboxylic acids: solubility and pharmacokinetic advantage of the glutarate salt. Mol Pharm 2013;10:4687-97.

8. Dhumal RS, Biradar SV, Yamamura S, Paradkar AR, York P. Preparation of amorphous cefuroxime axetil nanoparticles by sonoprecipitation for enhancement of bioavailability. Eur $\mathrm{J}$ Pharm Biopharm 2008;70:109-15.

9. Mourya VK, Inamdar N, Nawale RB, Kulthe SS. Polymeric micelles: general considerations and their applications. Indian J Pharm Educ Res 2011;45:128-38.

10. Gadade DD, Pekamwar SS. Pharmaceutical Cocrystals: regulatory and strategic aspects, design and development. Adv Pharm Bull 2016:6;479-94.

11. Qiao N, Li M, Schlindwein W, Malek N, Davies A, Trappitt G. Pharmaceutical cocrystals: an overview. Int J Pharm 2011;419:1-11

12. Yadav AV, Shete AS, Dabke AP, Kulkarni PV, Sakhare SS. Co-crystals: a novel approach to modify physicochemical properties of active pharmaceutical ingredients. Indian J Pharm Sci 2009;71:359-70.

13. https://www.fda.gov/downloads/Drugs/Guidances/ UCM281764.pdf.

14. O’Neil MJ. The Merck index: An Encyclopedia of Chemicals, Drugs and Biologicals. 14th ed. New Jersey: Merck and Co. Inc.; 2006. p. 5582.

15. Fule $\mathrm{R}$, Meer $\mathrm{T}$, Amin $\mathrm{P}$, Dhamecha $\mathrm{D}$, Ghadlinge $\mathrm{S}$. Preparation and characterisation of lornoxicam solid dispersion systems using hot melt extrusion technique. J Pharm Investig 2014;44:41-59.

16. Chemate SZ, Chowdary KP. A factorial study on enhancement of solubility and dissolution rate of lornoxicam employing hp-[beta]-cyclodextrin and surfactants. Int J Pharm Sci Res 2012;3:2252.

17. Mundada M, Wankhede S, Patwardhan S, Avachat A. Formulation and evaluation of topical gel of lornoxicam using a range of penetration enhancers. Indian J Pharm Edu Res. 2012;47:168-71.

18. Zhang GC, Lin HL, Lin SY. Thermal analysis and FTIR spectral curve-fitting investigation of formation mechanism and stability of indomethacin-saccharin cocrystals via solidstate grinding process. J Pharm Biomed Anal 2012;66:162-9.

19. Gadade DD, Pekamwar SS, Lahoti SR, Patni SD, Sarode MC. Cocrystallization of etodolac: prediction of cocrystallization, synthesis, solid state characterization and in vitro drug release. Marmara Pharm J 2017;21:78-88.

20. Higuchi TK, Connors A. Phase-solubility techniques. Adv Anal Chem Instrum 1965;4:117-212.

21. Singhvi G, Gampa G, Yadav N, Kumar V, Ukawala R. Design and evaluation of rapidly disintegrating tablets of racecadotril with enhanced in vitro dissolution achieved by solid dispersion technique. Indian J Pharm Edu Res 2013;47:56-63.

22. Aulton ME. Pharmaceutics: The science of dosage form design. 2nd ed. New York: Churchill Livingstone; 2002. p. 133-5. 
23. Jain A, Nayak S, Soni V. Iontophoretic permeation of lisinopril at different current densities and drug concentrations. Adv Pharm Bull 2012;2:239-44.

24. Shete AS, Yadav A, Murthy MS. Enhancement of dissolution rate of Irbesartan by Chitosan based Crystal Engineering Technique. Indian J Pharm Edu Res 2012;46:323-9.

25. Ravikumar N, Gaddamanugu G, Solomon KA. Structural, spectroscopic (FT-IR, FT-Raman) and theoretical studies of the 1: 1 cocrystal of isoniazid with p-coumaric acid. J Mol Struct 2013;1033:272-9.

26. Shewale S, Shete AS, Doijad RC, Kadam SS, Patil VA, Yadav AV. Formulation and solid state characterization of nicotinamide-based co-crystals of fenofibrate. Indian J Pharm Sci 2015;77:328-34.

27. Panchal KK, Chotai NP. formulation development and in vitro evaluation of controlled release matrix tablet of etodolac. Indian J Pharm Edu Res 2013;47:39-48.

28. Hickey MB, Peterson ML, Scoppettuolo LA, Morrisette SL, Vetter A, Guzmán H, et al. Performance comparison of a cocrystal of carbamazepine with marketed product. Eur J Pharm Biopharm 2007;67:112-9.

29. Trask AV, Motherwell WS, Jones W. Physical stability enhancement of theophylline via cocrystallization. Int J Pharm 2006;320:114-23.

30. Nakhat PD, Kondawar AA, Rathi LG, Yeole PG. Development and in vitro evaluation of buccoadhesive tablets of metoprolol tartrate. Indian J Pharm Sci 2008;70:121-24.

31. Sugandha K, Kaity S, Mukherjee S, Isaac J, Ghosh A. Solubility Enhancement of Ezetimibe by a Cocrystal Engineering Technique. Cryst Growth Des 2014;14:4475-86.

32. Alhalaweh A, Roy L, Rodriguez-Hornedo N, Velaga SP. $\mathrm{pH}$ Dependent Solubility of Indomethacin-Saccharin and Carbamazepine-Saccharin Cocrystals in Aqueous Media. Mol Pharm 2012;9:2605-12.

33. Jung, MS, Kim JS, Kim MS, Alhalaweh A, Cho W, Hwang SJ, et al. Bioavailability of indomethacin-saccharin cocrystals. J Pharm Pharmacol 2010;62:1560-68.

34. Lipert MP, Rodríguez-Hornedo N. Cocrystal transition points:
Role of cocrystal solubility, drug solubility, and solubilizing agents. Mol Pharm 2015;12:3535-46.

35. Elder DP, Holm R, de Diego HL. Use of pharmaceutical salts and cocrystals to address the issue of poor solubility. Int $\mathrm{J}$ Pharm 2013;453:88-100.

36. Brittain HG. Pharmaceutical Cocrystals: The Coming Wave of New Drug Substances. J Pharm Sci 2013;102:311-7.

37. Ahmed MO, Al-Badr AA. Lornoxicam. In: Brittain HG, editor. Profiles of drug substances, excipients and related methodology. 1st ed. Cambridge: Academic Press; 2011. p. 205-39.

38. Pavia DL, Lampman GM, Kriz GS. Introduction to spectroscopy: A Guide for Students of Organic Chemistry. 3rd ed. San Diego: Harcourt College Publishers; 2001. p.15.

39. Friščić T, Fábián L, Burley JC, Jones W, Motherwell WS. Exploring cocrystal-cocrystal reactivity via liquid-assisted grinding: the assembling of racemic and dismantling of enantiomeric cocrystals. Chem Commun 2006;48:5009-11.

40. Rehder S, Christensen NP, Rantanen J, Rades T, Leopold CS. High-shear granulation as a manufacturing method for cocrystal granules. Eur J Pharm Biopharm 2013;85:1019-30.

41. Mulye SP, Jamadar SA, Karekar PS, Pore YV, Dhawale SC. Improvement in physicochemical properties of ezetimibe using a crystal engineering technique. Powder Technol 2012;222:131-8.

42. Indian Pharmacopoeia. 6th ed. Ghaziabad: Indian Pharmacopoeia Commission; 2010. p. 193-752.

43. Heda AA, Gadade DD, Jagdale ND, Shinde NM, Puranik PK. Development of granisetron hydrochloride fast dissolving tablets: comparative evaluation of superdisintegrating agents. Res J Pharm Technol 2011;4:101-4.

44. Edge S, Steele DF, Staniforth JN, Chen A, Woodcock PM. Powder compaction properties of sodium starch glycolate disintegrants. Drug Dev Ind Pharm 2002;28:989-99.

45. Panzade P, Shendarkar GR. Pharmaceutical Cocrystal: An Antique and Multifaceted Approach. Curr Drug Deliv 2016;13;1-9. 